\title{
CS Research Square \\ Antitumor Effects of Lactate Transport Inhibition on Esophageal Adenocarcinoma Cells.
}

\section{Eduardo Chueca}

CIBEREHD

\section{Laura Grasa}

University of Zaragoza Faculty of Veterinary: Universidad de Zaragoza Facultad de Veterinaria

\section{Samantha Arechavaleta}

CIBEREHD

\section{María Asunción García-González}

Aragon Health Sciences Institute: Instituto Aragones de Ciencias de la Salud

\section{María Angeles Sáenz}

University of Zaragoza Faculty of Medicine: Universidad de Zaragoza Facultad de Medicina

\section{Angel Lanas}

IIS Aragón: Instituto de Investigacion Sanitaria Aragon

\section{Elena Piazuelo ( $\sim$ epiazor@unizar.es )}

Aragon Health Sciences Institute: Instituto Aragones de Ciencias de la Salud https://orcid.org/00000001-5813-3445

\section{Research Article}

Keywords: Esophageal adenocarcinoma, MCT, lactate, intracellular $\mathrm{pH}$, proton transport, hypoxia, glucose, apoptosis, proliferation.

Posted Date: July 22nd, 2021

DOl: https://doi.org/10.21203/rs.3.rs-69359/v2

License: (c) (i) This work is licensed under a Creative Commons Attribution 4.0 International License.

Read Full License 


\section{Abstract}

Background: As a consequence of altered glucose metabolism, cancer cells intake is increased, producing large amounts of lactate which is pumped out the cytosol by monocarboxylate transporters (MCTs).

MCTs are frequently overexpressed in tumors, MCT1 in the well oxygenated areas and MCT4 in hypoxic regions, and recent evidence has reported that MCT inhibition can exert antineoplastic effects, but this aspect has not been investigated in esophageal adenocarcinoma (EAC) yet. In the present study, MCT1 and MCT4 levels were assessed in EAC cells and the effects of MCT-1 selective inhibitor AZD3965, hypoxia and a glucose overload were evaluated in vitro.

Methods: Two EAC cell lines (OE33 and OACM5.1C) were treated with different concentrations of AZD3965 (10-100nM) in the presence or absence of a glucose overload under normoxic or hypoxic conditions and parameters of cytotoxicity, oxidative stress, intracellular $\mathrm{pH}(\mathrm{pHi})$ and lactate levels were evaluated.

Results: MCT1 was present in both cell lines whereas MCT4 was expressed in OE33 cells and only in a small population of the metastatic cells.

Glucose addition did not have any effect on apoptosis nor cell proliferation.

AZD3965 increased apoptosis and reduced proliferation of OACM5.1C cells, effects which were abrogated when cells were growing in hypoxia.

MCT1 inhibition increased intracellular lactate levels in all the cells evaluated, but this increase was higher in cells expressing only MCT1 and did not affect oxidative stress.

AZD3965 induced a decrease in pHi of cells displaying low levels of MCT4, and also increased NHE-1 expression on these cells.

Conclusion: These data provide in vitro evidence supporting the potential of MCT inhibitors as novel antineoplastic drugs for EAC and highlight the importance of achieving a complete MCT inhibition.

\section{Background}

The incidence of esophageal adenocarcinoma (EAC) has been increasing dramatically in the last decades in western countries [1]. The need for research of novel therapeutic strategies for this disease arises from the high resistance of this tumor to radio- and chemo-therapy linked to the fact that EAC is frequently diagnosed at advanced stages, resulting in poor prognosis and a 5-year survival rate lesser than $20 \%$ despite the use of combined therapies [2].

Abnormal pH homeostasis, an important hallmark of cancer cells, is related to increased proliferation, metastasis and resistance to chemotherapy, and the reversal of this aberrant $\mathrm{pH}$ gradient has been linked 
to decreased tumor growth and metastases [3-6]. Intracellular alkalinization and extracellular acidification is an early and crucial event in the neoplastic transformation which arises as a consequence of overexpression of proton transporters in response to expression of certain oncogenes [7-8]. Following intracellular alkalinization, tumor cells also display a shift in glucose metabolism from mitochondrial OXPHOS to aerobic glycolysis, a phenomenon called Warburg effect which generates large amounts of lactic acid and implicates an increased rate of glucose uptake due to the low efficiency of glycolysis in terms of ATP production. In this way, glucose consumption in cancer cells is not determined by the cellular needs but extracellular glucose levels and its intake is facilitated by overexpression of GLUT transporters (mainly GLUT1 and GLUT3) [9].

This phenomenon is being exploited for diagnostic purposes with Positron Emission Tomography but could also be applied with therapeutic fine e.g. to increase the cytotoxicity of some anticancer drugs, promoting lactic acid production and acidification in the tumor microenvironment by increasing the concentration of glucose. In this sense, previous works have shown that parental administration of glucose decreases $\mathrm{pH}$ selectively in tumor xenografts in rats without affecting systemic $\mathrm{pH}$ [10]. Interestingly, this effect was observed in tumors from different origins and histological types, and was maximum at the highest glucose level $(30 \mathrm{mM})$ evaluated, levels which can be achieved in clinical practice after intravenous infusion $[10,11]$.

To overcome the excess of acid production, cancer cells extrude protons through different transmembrane transporters among which monocarboxylate transporters (MCTs) catalyze the net transport of lactate anion with a proton. The MCT family spans 14 members of which MCT1 and MCT4 overexpression have been reported in several hematological and solid tumors such as lung, liver, colon, melanoma, glioblastoma, breast and ovarian cancers [12-14]. The distribution pattern of these MCTs varies among tumor types and even within the same tumor. MCT1 is expressed in the well-oxygenated areas of the tumor, whereas MCT4 expression is up-regulated in hypoxic areas through hypoxia-inducible factor 1a (HIF-1a), a major regulator of adaptation to hypoxic stress widely associated with cancer progression [13-16].

The relevance of targeting lactic acid transport and intracellular $\mathrm{pH}$ as an anticancer strategy is based on previous studies pointing out a link between a rise in extracellular lactate and increased cell migration, angiogenesis, escape of immune-surveillance and tumor aggressiveness [17-21]. Also besides, several studies over the last decade have shown that pharmacological inhibition of proton-coupled monocarboxylate transporters alone or in combination with other $\mathrm{pH}$ disruptors can exert important antineoplastic effects on different tumors, especially on those with higher metabolic demands [21-25]. Since MCT1 and MCT4 expression is increased in EAC compared to normal esophageal epithelium [26] and the effects of MCT1 blockade in esophageal adenocarcinoma have not been investigated yet, we conducted a study to analyze the expression of the lactate transporters MCT1 and MCT4 in EAC cell lines and evaluated whether pharmacological inhibition of the constitutive transporter MCT1 can exert antineoplastic effects on two different EAC cell lines. In this study we also examined the role that hypoxia 
and over-production of lactic acid induced by glucose overload could have on these effects and the cellular mechanisms involved.

\section{Materials And Methods}

\section{Drugs}

Selective MCT1 inhibitor AZD3965 was obtained from MedChemExpress (NJ, USA) Glucose, nigericin, Nacetylcysteine (NAC), RPMI-1640 and antibiotics were purchased from Sigma-Aldrich (Madrid, Spain). Fetal bovine serum (FBS) and C-SNARF-1 AM were both from ThermoFisher (Madrid, Spain). All compounds except glucose solution, which was dissolved in water, and NAC, which was dissolved in culture media, were dissolved in DMSO and made up with the media so that the final concentration of the vehicle was not $>0.04 \%(\mathrm{v} / \mathrm{v})$.

\section{Cell lines and Culture Conditions}

Two EAC cell lines were used in this study. OE33 cell line, established from an adenocarcinoma of the lower esophagus arising in $\mathrm{BE}$, and OACM 5.1C cells, established from a lymph node metastasis derived from a primary adenocarcinoma of the distal esophagus, were both purchased from ECACC (Salisbury, UK). Cells were cultured in RPMI-1640 supplemented with $10 \%$ FBS and $1 \%$ antibiotics (10000units $/ \mathrm{mL}$ penicillin and $10 \mathrm{mg} / \mathrm{mL}$ streptomycin). To induce an increase in lactic acid production and tumor cells acidification, cells were also grown under a glucose overload (30mM).

\section{MCT1 and MCT4 staining in EAC cell lines}

Cells were collected, fixed with $4 \%$ PFA and pelleted with $1 \%$ agarose. Immunocytochemical staining was performed in $2.5 \mu \mathrm{m}$ sample sections subjected to heat epitope retrieval at $\mathrm{pH} 9$ using the PT Link module (Dako, Madrid, Spain). The samples were then incubated with primary antibodies to MCT1 (sc-365501; Santa Cruz Biotechnology, Dallas, USA) at dilution 1/150 and MCT4 (sc-50329; Santa Cruz Biotechnology) at dilution 1/300 using an automatic staining system (Dako Autostainer Plus). Images were obtained using LAS EZ software (Leica, Barcelona, Spain) with a Leica DM 2500 microscope.

\section{RNA Extraction and qPCR Analysis of MCT1, MCT4, NHE1, CAIX and V-ATPase in cell lines}

The relative abundance of MCT1, MCT4, Sodium/hydrogen exchanger 1 (NHE-1), Carbonic anhydrase-IX (CA-IX) and Vacuolar-ATPase (V-ATPase) transporters in cell lines was measured by quantitative RT-PCR. Total RNA from EAC cell lines was isolated using the RNeasy Mini Kit (Qiagen, Hilden, Germany) followed by cDNA synthesis using the qScript cDNA superMix kit (Quanta bio, Beverly, MA, USA) according to the supplier's protocol. RT-PCR was performed with 200ng of cDNA using the StepOne Plus Real-Time PCR System (Life Technologies, Carlsbad, California, USA). Specific oligonucleotides for human MCT-1, MCT-4, SLC9A1(NHE-1), CA-IX and ATP6V1C1 (V-ATPase) expression were used and GAPDH and HPRT1 were selected as housekeeping genes (Table 1). 
Each sample was run in triplicate, the threshold cycle(CT) was determined and relative gene expression was expressed as follows: change in expression (fold) $=2^{-\Delta}(\Delta \mathrm{Ct})$ where $\Delta \mathrm{Ct}=\mathrm{Ct}$ (target)- Ct (housekeeping), and $\Delta(\Delta \mathrm{Ct})=\Delta \mathrm{Ct}$ (treated)- $\Delta \mathrm{Ct}$ (control).

Table 1

Primers used for quantification of transporters in OE33 and OAC cells by q-RT-PCR

\begin{tabular}{|c|c|c|}
\hline Gene & $\begin{array}{l}\text { GenBank accession } \\
\text { number }\end{array}$ & Sense and antisense primers \\
\hline MCT1 & NM_001166496.1 & $\begin{array}{l}\text { TTTCTTTGCGGCTTCCGTTGTTGTACGGA } \\
\text { TCAATTTACCCTTCAGCCCCATGG }\end{array}$ \\
\hline \multirow[t]{2}{*}{ MCT4 } & NM_001206952.1 & TTTTGCTGCTGGGCAACTTCTTCTG \\
\hline & & TCACGTTGTCTCGAAGCATGGGTTT \\
\hline \multirow{2}{*}{$\begin{array}{l}\text { SLC9A1 } \\
\text { (NEH1) }\end{array}$} & NM_003047.4 & ACCTGGTTCATCAACAAGTTCCG \\
\hline & & TTCACAGCCAACAGGTCTACCA \\
\hline \multirow[t]{2}{*}{ CAIX } & NM_001216.2 & САСТССТGСССТСТGАСТTС \\
\hline & & TCTCATCTGCACAAGGAACG \\
\hline \multirow[t]{2}{*}{ ATP6V1C1 } & NM_001695.4 & ATGACTGAGTTCTGGCTTATATC \\
\hline & & AGCTACTTTCTTAACCACTCC \\
\hline \multirow[t]{2}{*}{ HPRT1 } & NM_000194.2 & CCGGCTCCGTTATGGC \\
\hline & & GGTCATAACCTGGTTCATCATCA \\
\hline \multirow[t]{2}{*}{ GAPDH } & NM_001289746.1 & GAAGGTCGGAGTCAACGGATTT \\
\hline & & ATGGGTGGAATCATATTGGAA \\
\hline
\end{tabular}

\section{Apoptosis Assay}

The effects of AZD3965 (10-100nM) or vehicle alone (DMSO) in the presence or absence of glucose overload (30mM) were assessed by flow cytometry using the FACSAria cytometer (BD, Madrid, Spain). Cells were stained with Annexin V-FITC and propidium iodide (PI). Apoptotic cells were defined as Annexin $\mathrm{V}$ and Annexin $\mathrm{V}+\mathrm{PI}$ positive cells.

Cells were seeded in $25 \mathrm{~cm}^{2}$ cell culture flasks and cultured until reaching $40-50 \%$ confluence. Then, cells were treated, incubated $48 \mathrm{~h}$ under normoxic or hypoxic $\left(1 \% \mathrm{O}_{2}\right)$ conditions and collected for apoptosis determination. The experiments were repeated four times.

\section{Proliferation Assay}

Cell proliferation was measured using a BrdU assay kit (Roche, Barcelona, Spain) according to the manufacturer's manual. Briefly, EAC cells were seeded in 96-well plates and the next day AZD (10-100nM) 
or vehicle alone (DMSO) with or without glucose overload $(30 \mathrm{mM})$ was added. After an incubation period of $48 \mathrm{~h}$ under normoxic or hypoxic $\left(1 \% \mathrm{O}_{2}\right)$ conditions, cells were labeled with $\mathrm{BrdU}$ for $4 \mathrm{~h}$ and the labeling signal was quantified by measuring the relative absorbance $\left(A_{450}-A_{690} n m\right)$ with a plate reader (Synergy $\mathrm{HT}$, Biotek, Winooski, USA). Each assay was done in triplicate and the experiment was performed four times.

\section{Measurement of intracellular lactate levels}

Intracellular lactate levels were evaluated using a quantitative assay kit (Sigma-Aldrich) following the manufacturer instructions. Briefly, cells were treated with AZD3965 (10-100nM) or the vehicle (DMSO) with or without glucose overload $(30 \mathrm{mM})$ under normoxic or hypoxic $\left(1 \% \mathrm{O}_{2}\right)$ conditions for $48 \mathrm{~h}$. Cells were then collected and lysed using the lysis buffer included in the kit. Then, lysates were filtered with a $10 \mathrm{kDa}$ MWCO spin filter (Sigma-Aldrich) to remove lactate dehydrogenase. Absorbance was quantified with a plate reader (Synergy HT) at 570nm. Each sample was evaluated in duplicate and the experiment was repeated at least three times. The results, expressed as nmol lactate/mg protein were normalized according to the protein concentration in each sample, which was quantified in cell lysates before the filtrate through the $10 \mathrm{kDa}$ MWCO spin filter employing the BCA1 kit (Sigma-Aldrich).

\section{Evaluation of cytosolic $\mathrm{pH}$}

Intracellular $\mathrm{pH}(\mathrm{pHi})$ was evaluated in EAC cells by confocal microscopy using the $\mathrm{pH}$-sensitive fluorescent probe C-SNARF-1 AM (ThermoFisher) as previously described [27]. Cells were seeded in $35 \mathrm{x}$ $10 \mathrm{~mm}$ culture dishes and incubated at $37^{\circ} \mathrm{C} / 5 \% \mathrm{CO}_{2}$ in normoxia or hypoxia $\left(1 \% \mathrm{O}_{2}\right)$ for $48 \mathrm{~h}$ to achieve $50 \%$ confluence. Cells were then treated with AZD (100nM) or vehicle (DMSO) for $0.5,1,2$ hours and further stained with $5 \mu \mathrm{M}$ C-SNARF-1 AM in serum-free media for 20 min. pHi was determined in an LSM 880 confocal microscope (Zeiss, Madrid, Spain) by recording two fluorescence data (phase 1: $543 \mathrm{~nm}$ excitation-580nm emission and phase 2: $543 \mathrm{~nm}$ excitation-640 $\mathrm{nm}$ emission) and calculating the ratio (Phase2/Phase1), following the nigericin calibration procedure.

\section{Evaluation of reactive oxygen species (ROS)}

The analysis of ROS production was assessed in OE33 and OACM5.1C cells at different points after AZD addition using a quantitative assay (Abcam) based on ROS-sensitive probe DCFDA. Twenty-five thousand cells per well were seeded in 96-well plates and the next day DCFDA probe and AZD (100nM) were added and incubated at $37^{\circ} \mathrm{C}$. Intracellular ROS levels were evaluated every 60 minutes during 5 hours or after 24 hours of treatment and quantified as RFUs with respect to control cells measured at 495/529 nm using the Synergy HT plate reader (Biotek). To evaluate if the addition of the antioxidant NAC was able to reduce ROS levels, we also included cells treated with $5 \mathrm{mM} \mathrm{NAC}$ for $45 \mathrm{~min}$ before the addition of AZD.

\section{Statistical analysis}

Data analysis was performed using GraphPad (GraphPad Software, LaJolla, USA). Data were expressed as mean $\pm S E$. Differences between groups were analyzed by student $T$-test or by ANOVA as appropriate and $p<0.05$ was considered statistically significant. 


\section{Results}

\section{MCT1 and MCT4 expression in cell lines}

Immunocytochemistry revealed that both cell lines expressed MCT1 transporter (Fig. 1, A), whereas MCT4 expression was present in OE33 cells and only in a small population of the metastatic cell line (Fig. 1, B). To further confirm these results, we also quantified the relative expression of MCT4 in OE33 vs OACM 5.1C in normoxia and the results showed that MCT4 expression in OE33 cells was significantly higher $(122.09 \pm 20.31$ times, $p<0.01)$ than in the metastatic cell line (Fig. 1, C). We next sought to evaluate whether hypoxia was able to increase MCT4 expression in our cell models, and the results showed an increase in MCT4 expression in hypoxia with respect to normoxia of $174.3 \pm 18.8(p<0.01)$ times in OE33 and $54.41 \pm 13.15$ ( $p<0.01$ ) times in OACM5.1C (Fig. 1D and E, respectively). We finally compared the relative expression of MCT4 in OE33 vs OACM5.1C cells in hypoxia, and we observed again an important difference in the expression among both cell lines (508.78 \pm 54.87 times higher in OE33 cells, $p<0.01$ ) (Fig. 1, F).

\section{Effect of MCT1 inhibition on MCT1, MCT4, NHE-1, CA-IX and V-ATPase expression}

Since maintenance of intracellular $\mathrm{pH}$ is crucial for the survival of tumor cells $[5,6,24,28]$, we sought to evaluate whether MCT1 inhibition was able to trigger overexpression of different proton transporters involved in pHi homeostasis. We then evaluated the effects of MCT1 inhibition on MCT1, MCT4, NHE-1, V-ATPase and CA-IX expression by quantitative RT-PCR.

The results, expressed as the level of expression of the transporter in AZD3965-treated cells with respect to control cells (treated with vehicle alone), showed that treatment with AZD3965 for 48h did not affect MCT1 expression on any of the cell lines, whereas increased MCT4 expression on the metastatic cell line (Fig. 2, D).

Concerning other proton transporters, MCT1 inhibition did not affect OE33 cells NHE-1 expression (0.917 \pm 0.06 vs $1.00 \pm 0.03)$ but increased its expression on OACM5.1C cells ( $1.96 \pm 0.145$ vs $1.00 \pm 0.08, p<$ 0.01) (Fig. 3, A and B). V-ATPase (Fig. 3, C and D) and CA-IX (Fig. 3, E and F) were not significantly affected by AZD3965 in any of the EAC cell lines evaluated.

\section{MCT1 inhibition induced apoptosis and reduced cell proliferation of metastatic EAC cells}

Given that glucose intake in cancer cells is increased at higher extracellular concentrations, we evaluated the proapoptotic effects of MCT1 inhibitor AZD3965 in the presence of standard (11mM) and high $(30 \mathrm{mM})$ glucose levels under normoxic and hypoxic conditions. 
MCT1 inhibitor did not have any effect on apoptosis of the non-metastatic cells under any of the conditions evaluated (Fig. 4, A and B), whereas slightly increased apoptosis of the metastatic cell line only in normoxia (Fig. 4, C). The addition of glucose did not affect apoptosis of EAC cells.

Since AZD3965 had different effects on apoptosis of EAC cells under normoxia and hypoxia, we next sought to test in the same conditions the effects of the inhibitor on cell proliferation in both cell lines. The results, expressed as \% of BrdU incorporation in AZD3965-treated cells with respect to control cells, showed that the inhibitor did not affect proliferation of OE33 cells (Fig. 5, A and B), whereas significantly inhibited cell proliferation of the metastatic cells in normoxia (Fig. 5, C) but not under hypoxia (Fig. 5, D). Glucose did not exert any effect on cell proliferation on any of the cell lines.

\section{MCT1 inhibitor increased intracellular lactate levels}

We evaluated the effect of AZD3965 on intracellular lactate concentration alone or in the presence of a glucose overload $(30 \mathrm{mM})$ under normoxic or hypoxic conditions.

MCT1 blockade significantly increased intracellular lactate levels in EAC cell lines at 100 and $10 \mathrm{nM}$ both in normoxia (Fig. 6, A) and hypoxia (Fig. 6, B), but this increase was higher in the metastatic cell line. OE33 cells in normoxia displayed similar intracellular lactate levels to those observed in hypoxia, whereas OACM5.1C cells grown in normoxia exhibited higher levels than hypoxic cells. Glucose overload had little effect on EAC cells in normoxia but induced a marked increase in intracellular lactate in hypoxia.

\section{MCT1 inhibition reduced intracellular $\mathrm{pH}$ of metastatic cells}

We treated cells with AZD (100nM) for 0.5, 1 and 2 hours to evaluate whether MCT1 inhibitor was able to promptly induce changes in pHi in EAC cells. The results showed a basal alkaline intracellular pH in OE33 cells $(7.86 \pm 0.048)$ that was not significantly affected by AZD after 30 minutes $(7.84 \pm 0.093), 1$ hour (7.83 \pm 0.049$)$ and 2 hours $(7.78 \pm 0.068)$ of treatment. (Fig. 7, A) Conversely, the metastatic cell line displayed a basal intracellular $\mathrm{pHi}$ of $7.40 \pm 0.023$, and AZD reduced $\mathrm{pHi}$. After 30 minutes of treatment, there was a significant reduction in $\mathrm{pHi}(7.29 \pm 0.022, \mathrm{p}<0.05)$, which was maximum after 1 hour $(7.21 \pm$ $0.022, p<0.05)$. After 2 hours, $\mathrm{pHi}$ increased but remained reduced in comparison to control cells $(7.34 \pm$ $0.012, p<0.05)(F i g .7, B)$. Due that only the metastatic cells were affected by AZD, we then sought to test whether MCT1 inhibition also affected pHi under hypoxic conditions in this cell line. The results showed that in hypoxia, basal pHi was $7.58 \pm 0.18$, and AZD did not significantly affect intracellular pH after 30 minutes $(7.46 \pm 0.11), 1$ hour $(7.52 \pm 0.17)$ nor 2 hours $(7.63 \pm 0.17)$ (Fig. 7, C).

\section{AZD3965 did not affect ROS levels in EAC cells}

We first studied whether there was a short-term increase in ROS production after adding AZD3965 to EAC cells. The results, expressed as RFUs, showed that MCT1 blockade did not affect ROS production on EAC cells five hours after adding the treatment (Fig. 8A and B). However, a slight but not significant timedependent increase in ROS was seen in AZD3965-treated cells, and therefore we sought to evaluate ROS 
levels after 24 hours of treatment. As shown in Fig. 8C and D, treatment with MCT1 inhibitor for 24 hours did not affect ROS production in OE33 nor OACM5.1C cells with respect to control cells.

\section{Discussion}

Despite its lower efficiency in ATP production in comparison to oxidative phosphorylation, glycolysis is a quick pathway to provide energy and metabolic precursors for fast proliferating cells. Tumor cells rely on high glucose consumption and also on the ability to continuously pump out the large amounts of lactate and $\mathrm{H}+$ generated by their metabolism to maintain the glycolytic process and to avoid intracellular acidification and metabolic inhibition caused by lactate accumulation. In this study, we attempted to force intracellular acidosis of esophageal tumor cells and, as a consequence, cell death, by increasing glucose concentration in culture medium and simultaneously inhibiting the removal of $\mathrm{H}+$ and lactate produced by using the selective MCT1 inhibitor AZD3965. Although treatment of cells with AZD3965 induced a significant decrease of $\mathrm{pHi}$ and cell proliferation and an increase of cell apoptosis in one cell line, higher glucose concentration in culture medium did not have any effect on the cytotoxicity of the MCT1 inhibitor in any of the cell lines used. It is possible that our cell lines exhibit a phenotype that makes them insensitive to glucose overload as it has been previously described that multidrug-resistant cancer cells were unaffected by high glucose levels while drug-sensitive cells exhibited increased proliferation rates in response to glucose as a consequence of low PKC- $\beta$ II expression [29].

Monocarboxylate influx and efflux is an active process carried out by MCTs, of which MCT1 and MCT4 have shown to play a key role in maintaining an alkaline pHi in tumors [11]. Lactate is the main substrate for MCTs, and in vitro and in vivo studies have demonstrated that a blockade of lactate export and the subsequent pHi disruption is an effective strategy to target highly glycolytic tumor cells $[15,23,24,28$, 30]. In this context, the pharmacological MCT1 inhibitor AZD3965 is currently undergoing a phase I study in patients with advanced cancer (NCT01791595).

Our data demonstrate that sensitivity to the cytotoxic effects of MCT1 inhibition varies among cell lines and also depends on oxygen levels. In normoxia, metastatic EAC cells were affected by MCT1 inhibition whereas the non-metastatic cell line remained unaffected, and both cell lines were insensitive to AZD3965 under hypoxia. Previous works showed that co-expression of both MCT1 and MCT4 transporters was related to resistance to MCT1 inhibition, which is consistent with functional redundancy of MCTs [23, 30,31]. Moreover, MCT4 knockdown or silencing in different highly aggressive cancer models in vivo and in vitro has been reported to make them sensitive to MCT1 inhibition [22, 31]. In our study, immunocytochemistry showed that metastatic OACM 5.1C cells in normoxia expressed high levels of MCT1, with only a small proportion of the cells expressing MCT4, while OE33 cells expressed both MCT1 and MCT4 and remained unaffected by AZD3965 treatment. According to these results, we next sought to evaluate whether incubation under hypoxic conditions was able to increase MCT4 expression in our cell lines, as previous studies demonstrated that hypoxia induces MCT4 expression through HIF1-a $[17,32]$. In line with these studies, both OE33 and OACM5.1C cells showed an increase in MCT4 expression after 48 hours growing in hypoxia, and thus AZD3965 effects on the metastatic cell line were 
completely abolished, suggesting that complete inhibition of MCTs is required to exert antineoplastic effects. Thus, empirical results reported in the present study should be considered in the light of the limitation of the lack of simultaneous pharmacological inhibition of both MCTs, since to date there are no commercially available MCT4 selective inhibitors.

In this work, we decided to evaluate apoptosis and proliferation after $48 \mathrm{~h}$ of treatment based on previous studies with our cell model in which we observed only a slight effect in apoptosis when apoptotic inducers were used for less than 48 hours.

Our results showed that MCT1 inhibition in normoxia induced growth arrest and had little effect on apoptosis on AZD3965 sensitive cells, effects which could be induced at least partially by the intracellular acidification observed in these cells. To further elucidate the cellular mechanisms involved in the observed cytotoxic effects, in the present work we also evaluated pHi and lactate after AZD3965 addition. Under normoxic conditions MCT1 inhibition decreased pHi of OACM 5.1C cells but not OE33 cells and raised intracellular lactate levels in both EAC cell lines. However, this increase in lactate was remarkably higher in the metastatic cell line, which together with the effects on pHi seemed to be a consequence of the different levels of expression of MCTs between the cell lines. It should be noted that intracellular acidification in OACM 5.1C cells may have been softened by the increase in MCT4 and NHE-1 expression, a proton pump implicated in pHi regulation in several tumors [33-36] observed after AZD3965 addition. Previous studies showed that acidification triggers NHE-1 expression and this response allow cells to fight the lethal cell acidosis [37]. Since OE33 cells expressed both MCT1 and MCT4 transporters, there was no variation on $\mathrm{pH}$ levels and thus expression of NHE-1 remained unaffected after AZD3965 addition.

As previously seen, intracellular acidification affects a wide range of cellular processes like cell growth, through a blockade in $\mathrm{G} 2 / \mathrm{M}$ entry and completion of S phase due to mTORC1 inhibition in response to intracellular acidic stress [5, 30,38-43]. Although the magnitude of internal $\mathrm{pH}$ changes observed in the metastatic cells after treatment with AZD3965 was small, previous reports observed on melanoma cells showed that even a slight variation on intracellular $\mathrm{pH}$ seems to be able to induce cell growth arrest [44]. Intracellular acidification has also been linked to increased apoptosis in cancer cells, creating the optimal conditions for the activation of caspases and different apoptotic pathways [45-46]. In this study MCT1 inhibition increased apoptosis in OACM $5.1 \mathrm{C}$ cells, but these effects may have been lowered as a consequence of the small drop observed in intracellular $\mathrm{pH}$.

In line with these results, it is feasible that we did not observe effects on intracellular $\mathrm{pH}$, apoptosis nor cell proliferation upon MCT1 blockade in both cell lines growing under hypoxia as a consequence of MCT4 increased expression. Results also showed that in these conditions, lactate increased to a lesser extent than in normoxia.

Finally, we evaluated the effects of MCT1 inhibition on intracellular ROS levels. High intracellular lactate levels have been previously linked with cytotoxic effects as a consequence of an increase in oxidative stress. It has been proposed that lactate accumulation might disrupt glycolytic flux and, thus, increase 
ROS production through enhanced mitochondrial respiration to maintain ATP homeostasis [22, 33, 47]. This was not the case for OE33 and OACM5.1C cells, in which treatment with MCT1 inhibitor at different times did not affect ROS levels, a result consistent with the antioxidant character of lactate [48], suggesting that in our model AZD3965-induced cytotoxic effects might be independent of ROS generation.

The present work has shown that targeting MCTs is an effective strategy to inhibit tumor growth of EAC cells by inducing an increase in intracellular lactate levels and a decrease in intracellular $\mathrm{pH}$ when effective inhibition of lactate and protons efflux is achieved. In this sense, and considering the fact that within a tumor there is a continuous shuttling of lactate among highly glycolytic hypoxic tumor cells, pumping out lactate through MCT4, and oxidative tumor cells which can import and use the monocarboxylate as a source of energy, in addition to the cytotoxic effects that intracellular acidification exerts on tumor cells, the need for developing selective and potent proton and lactate transporters inhibitors arises as a valuable anticancer therapy.

\section{Conclusions}

-Pharmacological inhibition of MCT1 transporter exerted antineoplastic effects in EAC cells with low MCT4 expression, mainly by inhibiting proliferation, and in a lesser extent by inducing apoptosis.

-Increased extracellular glucose concentration did not modify the antitumor effect of MCT1 inhibition in these cell lines.

-Although MCT1 inhibition was associated to increased intracellular levels of lactate independently of MCT4 expression, cell acidification was only achieved when low levels of MCT4 transporter were expressed in EAC cells.

-Hypoxia was associated to an increase of MCT4 expression and abrogated the antitumor effect of MCT1 inhibition.

\section{Abbreviations}

Esophageal adenocarcinoma (EAC), monocarboxylate transporters (MCTs), Intracellular $\mathrm{pH}(\mathrm{pHi})$, hypoxia-inducible factor 1a (HIF-1a), N-acetylcysteine (NAC), Fetal bovine serum (FBS), Sodium/hydrogen exchanger 1 (NHE-1), Carbonic anhydrase-IX (CA-IX), Vacuolar-ATPase (V-ATPase), reactive oxygen species (ROS).

\section{Declarations}

\section{Ethics approval and consent to participate}

Not applicable 


\section{Consent for publication}

Not applicable

\section{Availability of data and materials}

The datasets used and/or analysed during the current study are available from the corresponding author on reasonable request.

\section{Competing interests}

The authors declare that they have no competing interests.

\section{Funding}

This study was supported with a grant from Instituto de Salud Carlos III (PI14/01931)

\section{Author's contributions}

EC performed most of experiments and wrote the paper.

LG was involved in qPCR studies.

SA was involved in cell culture and pHi analysis.

MAGG was involved in immunocytochemical analysis.

AL was involved in the revision of the work and provided vital reagents.

MAS was involved in the revision of the work.

EP was involved in the conception and design of the study, provided vital reagents and analytical tools and collaborated in the edition of the paper.

\section{Acknowledgements}

Not applicable.

\section{References}

1. Edgren G, Adami HO, Weiderpass E, Nyrén O (2013) A global assessment of the oesophageal adenocarcinoma epidemic. Gut 62:1406-1414. http://dx.doi.org/10.1136/gutjnl-2012-302412

2. Hur C, Miller M, Kong CY, Dowling EC, Nattinger KJ, Dunn M (2013) Trends in esophageal adenocarcinoma incidence and mortality. Cancer 119:1149-1158. https://doi.org/10.1002/cncr.27834 
3. Raghunand N, Mahoney B, vanSluis R, Baggett B, Gillies RJ (2001) Acute metabolic alkalosis enhances response of $\mathrm{C} 3 \mathrm{H}$ mouse mammary tumors to the weak base mitoxantrone. Neoplasia 3:227-235. https://doi.org/10.1038/sj.neo.7900151

4. Luciani F, Spada M, DeMilito A, Molinari A, Rivoltini L, Montinaro A (2004) Effect of proton pump inhibitor pretreatment on resistance of solid tumors to cytotoxic drugs. J Natl Cancer Inst 96:17021713. https://doi.org/10.1093/jnci/djh305

5. Rofstad EK, Mathiesen B, Kindem K, Galappathi K (2006) Acidic extracellular pH promotes experimental metastasis of human melanoma cells in athymic nude mice. Cancer Res 66:66996707. https://doi.org/10.1158/0008-5472.can-06-0983

6. DeMilito A, Canese R, Marino ML, Borghi M, lero M, Villa A,et al. (2010) pH dependent antitumor activity of proton pump inhibitors against human melanoma is mediated by inhibition of tumor acidity. Int J Cancer 127:207-219. https://doi.org/10.1002/ijc.25009 0

7. Reshkin SJ, Bellizzi A, Caldeira S, Albarani V, Malanchi I, Poignee M, et al. (2000) Na+/H + exchanger dependent intracellular alkalinization is an early event in malignant transformation and plays an essential role in the development of subsequent transformation- associated phenotypes. FASEB J. 14:2185-97. https://doi.org/10.1096/fj.00-0029com

8. Harguindey S, Arranz JL, Polo Orozco JD, Rauch C, Fais S, Cardone RA, Reshkin SJ (2013) Cariporide and other new and powerful NHE1 inhibitors as potentially selective anticancer drugs-an integral molecular/biochemical/metabolic/clinical approach after one hundred years of cancer research. $\mathrm{J}$ Transl Med. 2013;11:282. https://dx.doi.org/10.1186\%2F1479-5876-11-282

9. Ancey PB, Contat C, Meylan E (2018) Glucose transporters in cancer - from tumor cells to the tumor microenvironment. FEBS J. 285:2926-2943. https://doi.org/10.1111/febs.14577

10. Volk T, JÄhde E, Fortmeyer HP, Glüsenkamp K-H, Rajewsky MF (1993) pH in human tumour xenografts: effect of intravenous administration of glucose. Br J Cancer 68: 492-500 https://dx.doi.org/10.1038\%2Fbjc.1993.375

11. Jähde E, Rjewsky MF (1982) Tumor-selective modification of cellular microenvironment in vivo: effect of glucose infussion on the $\mathrm{pH}$ in normal and malignant rat tissues. Cancer Res 42:15051512

12. Pinheiro C, Longatto-Filho A, Azevedo-Silva J, Casal M, Schmitt FC, Baltazar F (2012) Role of monocarboxylate transporters in cancer: state of the art. J Bioenerg Biomembr 44:127-139. https://doi.org/10.1007/s10863-012-9428-1

13. Spugnini EP, Sonveaux P, Stock C, Perez-Sayans M, De Milito A, Avnet S, et al. (2015) Proton channels and exchangers in cancer. Biochim Biophys Acta. 1848: 2715-26. https://doi.org/10.1016/j.bbamem.2014.10.015

14. Fang J, Quinones QJ, Holman TL, Morowitz MJ, Wang Q, Zhao H, et al. (2006) The H+- linked monocarboxylate transporter (MCT1/SLC16A1):a potential therapeutic target for high-risk neuroblastoma. Mol Pharmacol. 70: 2108-15. https://doi.org/10.1124/mol.106.026245 
15. Sonveaux P, Végran F, Schroeder T, Wergin MC, Verrax J, Rabbani ZN et al (2008) Targeting lactatefueled respiration selectively kills hypoxic tumor cells in mice. J Clin Invest 118:3930-3942. https://dx.doi.org/10.1172\%2FJCl36843

16. Rademakers SE, Lok J, van der Kogel AJ, Bussink J, Kaanders JH (2011) Metabolic markers in relation to hypoxia; staining patterns and colocalization of pimonidazole, HIF-1a, CAIX, LDH-5, GLUT1, MCT1 and MCT4. BMC Cancer 11:167. https://doi.org/10.1186/1471-2407-11-167

17. Ullah MS, Davies AJ, Halestrap AP (2006) The plasma membrane transporter MCT4, but not MCT1, is up-regulated by hypoxia through a HIF-1 alpha-dependent mechanism. J Biol Chem 281:90309037. https://doi.org/10.1074/jbc.m511397200

18. Kumar VB, Viji RI, Kiran MS, Sudhakaran PR (2007) Endothelial cell response to lactate: implication of PAR modification of VEGF. J Cell Physiol 211:477-485. https://doi.org/10.1002/jcp.20955

19. Goetze K, Walenta S, Ksiazkiewicz M, Kunz-Schughart LA, Mueller-Klieser W (2011) Lactate enhances motility of tumor cells and inhibits monocyte migration and cytokine release. Int $\mathrm{J}$ Oncol 39:453463. https://doi.org/10.3892/ijo.2011.1055

20. Baumann F, Leukel P, Doerfelt A, Beier CP, Dettmer K, Oefner PJ et al (2009) Lactate promotes glioma migration by TGF-beta2-dependent regulation of matrix metalloproteinase-2. Neuro Oncol 11:368380. https://doi.org/10.1215/15228517-2008-106

21. Fischer K, Hoffmann P, Voelkl S, Meidenbauer N, Ammer J, Edinger M et al (2007) Inhibitory effect of tumor cell-derived lactic acid on human T-cells. Blood 109:3812-3819.

https://doi.org/10.1182/blood-2006-07-035972

22. Marchiq I, Le Floch R, Roux D, Simon MP, Pouyssegur J (2015) Genetic disruption of lactate/H + symporters (MCTs) and their subunit CD147/BASIGIN sensitizes glycolytic tumor cells to phenformin. Cancer Res 75:171-180. https://doi.org/10.1158/0008-5472.can-14-2260

23. Polański R, Hodgkinson CL, Fusi A, Nonaka D, Priest L, Kelly P et al (2014) Activity of the monocarboxylate transporter 1 inhibitor AZD3965 in small cell lung cancer. Clin Cancer Res 20:926937. https://doi.org/10.1158/1078-0432.ccr-13-2270

24. Bola BM, Chadwick AL, Michopoulos F, Blount KG, Telfer BA, Williams KJ et al (2014) Inhibition of monocarboxylate transporter-1 (MCT1) by AZD3965 enhances radiosensitivity by reducing lactate transport. Mol Cancer Ther 13:2805-2816. https://doi.org/10.1158/1535-7163.mct-13-1091

25. Hanson DJ, Nakamura S, Amachi R, Hiasa M, Oda A, Tsuji D, et al. (2015) Effective impairment of myeloma cells and their progenitors by blockade of monocarboxylate transportation. Oncotarget. 6:33568-86. https://doi.org/10.18632/oncotarget.5598

26. Huhta H, Helminen O, Palomäki S, Kauppila JH, Saarnio J, Lehenkari PP, et al. (2017) Intratumoral lactate metabolism in Barrett's esophagus and adenocarcinoma. Oncotarget 8:22894-22902. https://www.oncotarget.com/article/15284/text/ 0

27. Lucien F, Harper K, Pelletier PP, Volkov L, Dubois CM. (2014) Simultaneous pH measurement in endocytic and cytosolic compartments in living cells using confocal microscopy. J Vis Exp. 28:51395 https://doi.org/10.3791/51395 
28. SK Parks, J Chiche, J Pouysségur. (2013) Disrupting proton dynamics and energy metabolism for cancer therapy. Nat Rev Cancer. 13: 611-623 https://doi.org/10.1038/nrc3579

29. Yamamoto M, Patel NA, Taggart J, Sridhar R, Cooper DR. (1999) A shift from normal to high glucose levels stimulates cell proliferation in drug sensitive MCF-7 human breast cancer cells but not in multidrug resistant MCF-7/ADR cells which overproduce PKC-betall. Int J Cancer. 83:98-106. https://doi.org/10.1002/(sici)1097-0215(19990924)83:1\%3C98::aid-ijc18\%3E3.0.co;2-v

30. Morais-Santos F, Miranda-Gonçalves V, Pinheiro S, Vieira AF, Paredes J, Schmitt FC et al (2013) Differential sensitivities to lactate transport inhibitors of breast cancer cell lines. Endocr Relat Cancer 21:27-38. https://doi.org/10.1530/erc-13-0132

31. Le Floch R, Chiche J, Marchiq I, Naiken T, Ilc K, Murray CM et al (2011) CD147 subunit of lactate/H + symporters MCT1 and hypoxia-inducible MCT4 is critical for energetics and growth of glycolytic tumors. Proc Natl Acad Sci USA 108:16663-16668. https://doi.org/10.1073/pnas.1106123108

32. Pérez de Heredia F, Wood IS, Trayhurn P. (2010) Hypoxia stimulates lactate release and modulates monocarboxylate transporter (MCT1, MCT2, and MCT4) expression in human adipocytes. Pflugers Arch. 459:509 - 18. https://doi.org/10.1007/s00424-009-0750-3

33. Colen CB, Seraji-Bozorgzad N, Marples B, Galloway MP, Sloan AE, Mathupala SP (2006) Metabolic remodeling of malignant gliomas for enhanced sensitization during radiotherapy: an in vitro study. Neurosurgery. 59:1313-23;discussion1323-4 https://doi.org/10.1227/01.neu.0000249218.65332.bf

34. Harguindey S, Orive G, Luis Pedraz J, Paradiso A, Reshkin SJ. (2005) The role of pH dynamics and the $\mathrm{Na}+\mathrm{H}+$ antiporter in the etiopathogenesis and treatment of cancer. Two faces of the same coinone single nature. Biochim Biophys Acta 1756:1-24. https://doi.org/10.1016/j.bbcan.2005.06.004 0

35. Aravena C, Beltrán AR, Cornejo M, Torres V, Díaz ES, Guzmán-Gutiérrez E et al (2012) Potential role of sodium-proton exchangers in the low concentration arsenic trioxide-increased intracellular $\mathrm{pH}$ and cell proliferation. PLoS One 7: e51451 https://dx.doi.org/10.1371\%2Fjournal.pone.0051451

36. Wahl ML, Owen JA, Burd R, Herlands RA, Nogami SS, Rodeck U, et al. (2002) Regulation of intracellular pH in human melanoma: potential therapeutic implications. Mol Cancer Ther. 1:617 28.

37. Singh G, McAteer JA, Soleimani M. (1995) The effect of lethal acid stress on $\mathrm{Na}+/ \mathrm{H}+$ exchanger isoforms in cultured inner medullary collecting duct cells: deletion of NHE-2 and over expression of NHE-1. Biochim Biophys Acta. 1239:74-80. https://doi.org/10.1016/0005-2736(95)00148-v

38. Doherty JR, Yang C, Scott KE, Cameron MD, Fallahi M, Li W, et al. (2014) Blocking lactate export by inhibiting the Myc target MCT1 Disables glycolysis and glutathione synthesis. Cancer Res. 74:908 20. https://doi.org/10.1158/0008-5472.can-13-2034

39. Mathupala SP, Parajuli P, Sloan AE (2004) Silencing of monocarboxylate transporters via small interfering ribonuceic acid inhibits glicólisis and induces cell death in malignant glioma: an in vitro study. Neurosurgery 55:1410-1419. https://doi.org/10.1227/01.neu.0000143034.62913.59 discussion 1419. 
40. Pouysségur J, Franchi A, L'Allemain G, Paris S (1995) Cytoplasmic pH, a key determinant of growth factor-induced DNA synthesis in quiescent fibroblasts. FEBS Lett 190:115-119. https://doi.org/10.1016/0014-5793(85)80439-7

41. Lagadic-Gossmann D, Huc L, Lecureur V (2004) Alterations of intracellular pH homeostasis in apoptosis: origins and roles. Cell Death Differ 11:953-961. https://doi.org/10.1038/sj.cdd.4401466

42. Putney LK, Barber DL. (2003) Na-H exchangedependent increase in intracellular pH times G2/M entry and transition. J Biol Chem. 278:44645-9. https://doi.org/10.1074/jbc.m308099200

43. Chambard JC, Pouyssegur J. (1986) Intracellular pH controls growth factor-induced ribosomal protein $\mathbf{S 6}$ phosphorylation and protein synthesis in the $\mathrm{GO}-\mathbf{G} 1$ transition of fibroblasts. Exp Cell Res 164:282-94. https://doi.org/10.1016/0014-4827(86)90029-7

44. Musgrove E, Seaman M, Hedley D. (1987) Relationship between cytoplasmic pH and proliferation during exponential growth and cellular quiescence. Exp Cell Res. 172:65-75. https://doi.org/10.1016/0014-4827(87)90093-0

45. De Milito A, Canese R, Marino ML, Borghi M, lero M, Villa A et al (2010) pH-dependent antitumor activity of proton pump inhibitors against human melanoma is mediated by inhibition of tumor acidity. Int J Cancer 127:207-219. https://doi.org/10.1002/ijc.25009

46. Hirpara JL, Clément MV, Pervaiz S (2001) Intracellular acidification triggered by mitochondrialderived hydrogen peroxide is an effector mechanism for drug-induced apoptosis in tumor cells [retracted in: J Biol Chem. 2014 289:10269]. J Biol Chem. 276:514-521.

https://doi.org/10.1074/jbc.m004687200

47. Granja S, Marchiq I, Le Floch R, Moura CS, Baltazar F, Pouysségur J (2015) Disruption of BASIGIN decreases lactic acid export and sensitizes non-small cell lung cancer to biguanides independently of the LKB1 status. Oncotarget 6:6708-6721. https://doi.org/10.18632/oncotarget.2862

48. Groussard C, Morel I, Chevanne M, Monnier M, Cillard J, Delamarche A (2000) Free radical scavenging and antioxidant effects of lactate ion: an in vitro study. J Appl Physiol 89:169-175. https://doi.org/10.1152/jappl.2000.89.1.169

\section{Figures}


A
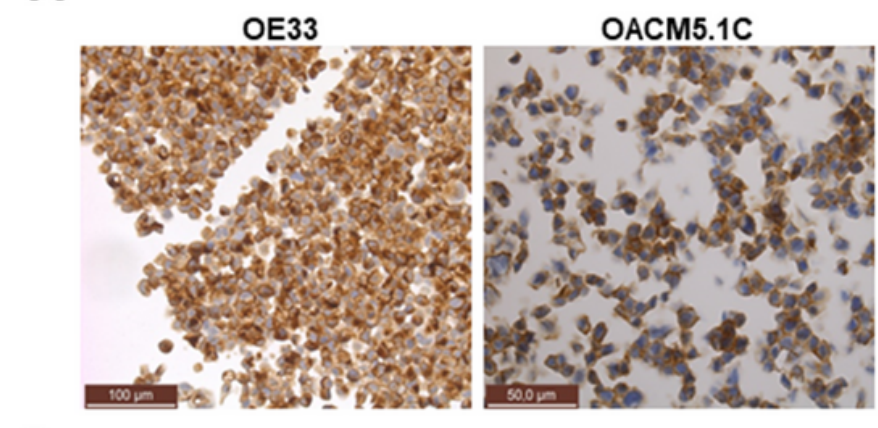

C

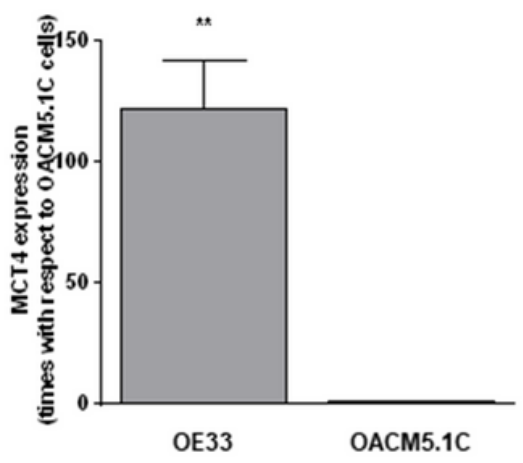

E

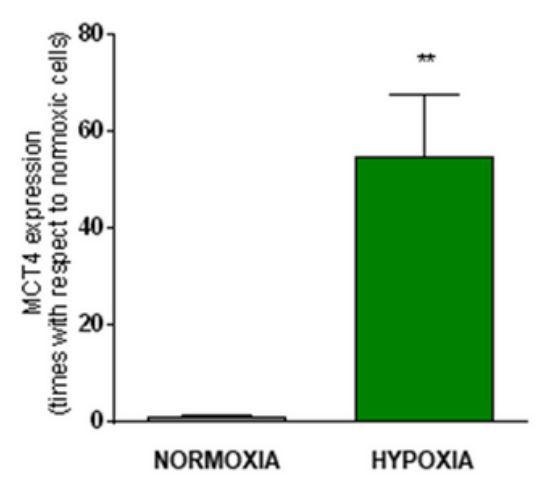

B

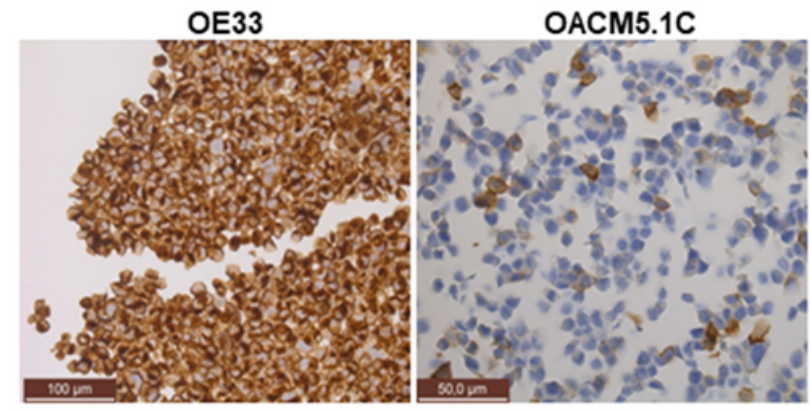

D

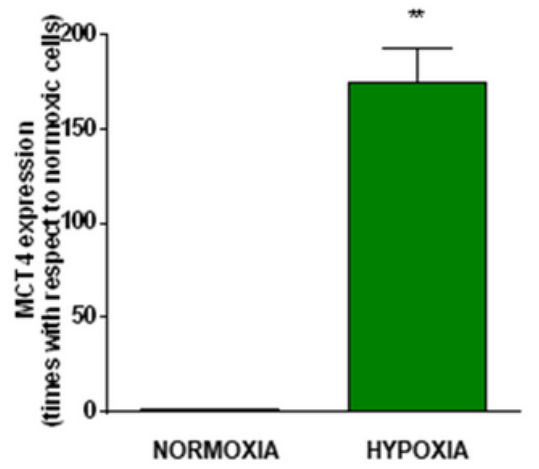

$\mathbf{F}$

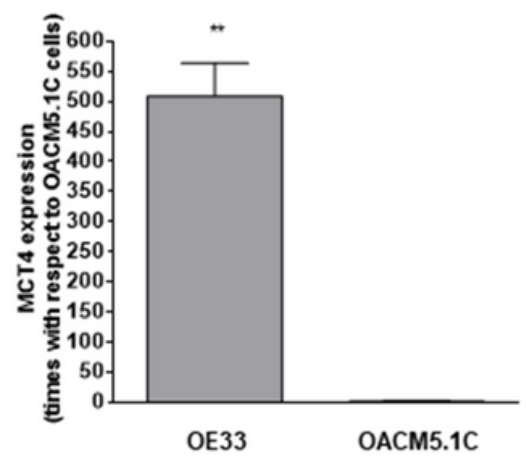

\section{Figure 1}

MCT1 and MCT4 expression in cell lines. Immunocytochemical labeling of MCT1 (A) and MCT4 (B) in OE33 and OACM5.1C cell lines. MCT4 relative expression was evaluated by RT-qPCR comparing both cell lines in normoxia (C), comparing each cell line in normoxia vs hypoxia (OE33, D ; OACM5.1C, E) and comparing both cell lines in hypoxia (F). GAPDH and HPRT1 were selected as housekeeping genes. Significant level ${ }^{\star \star} p<0.01$. 
A

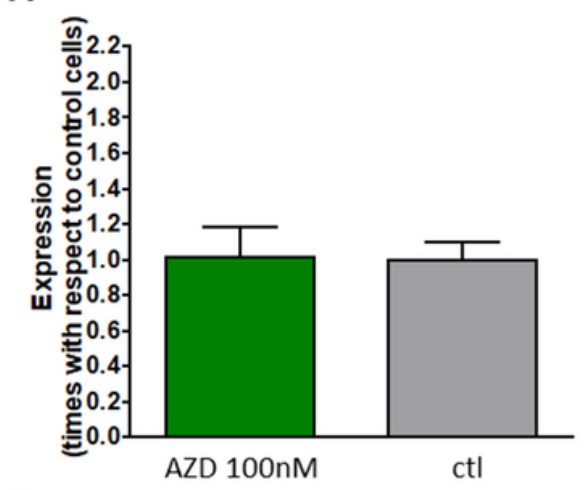

C

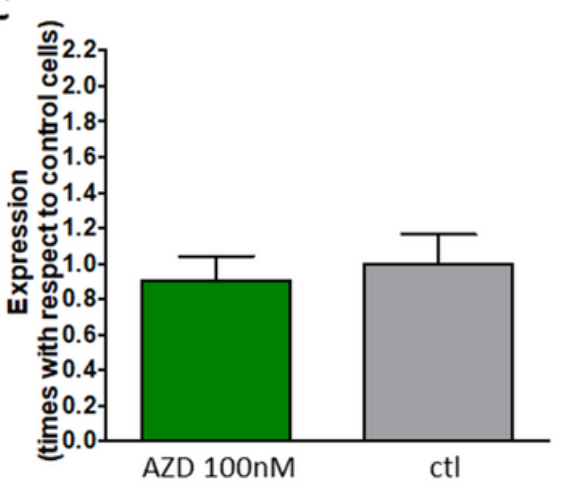

B

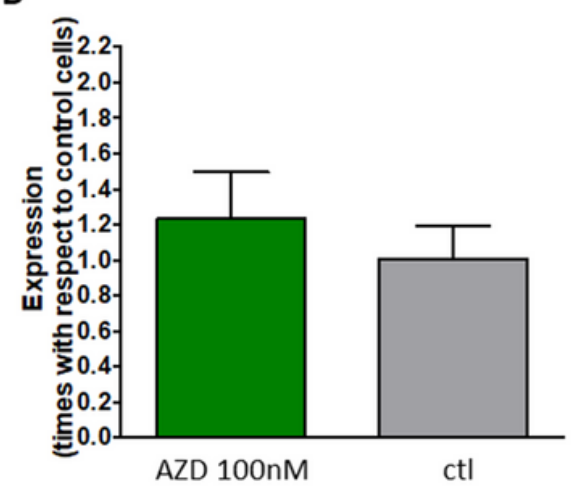

D

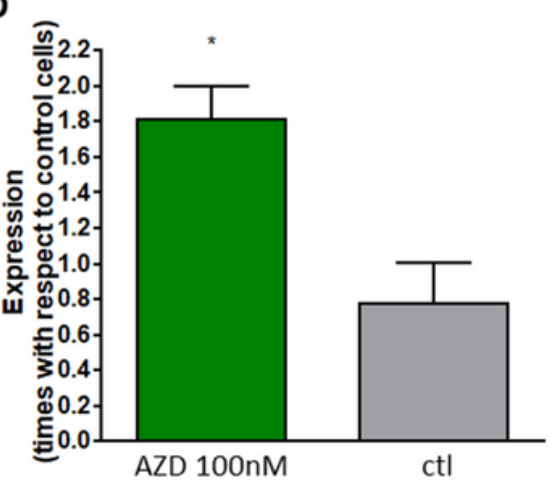

Figure 2

MCT1 and MCT4 relative expression in AZD3965-treated cells. MCT1 relative expression in OE33 (A), OACM5.1C cells (B), and MCT4 relative expression in OE33 (C) and OACM5.1C cells (D) was evaluated by RT-qPCR after treatment with AZD3965 (100nM) for 48 hours and the results are expressed as the level of expression of the transporters with respect to cells treated with the vehicle alone. GAPDH and HPRT1 were selected as housekeeping genes. Significant level * $p<0.05$. 
A

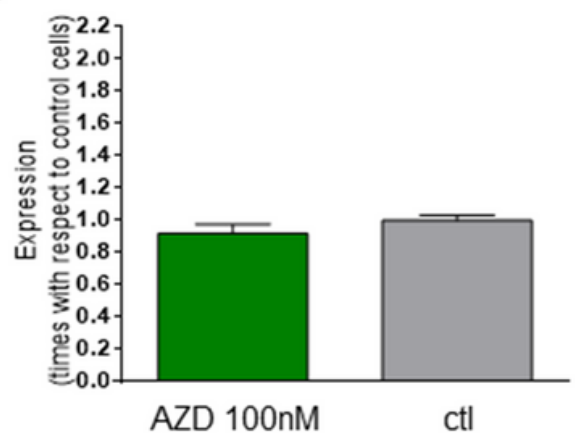

C
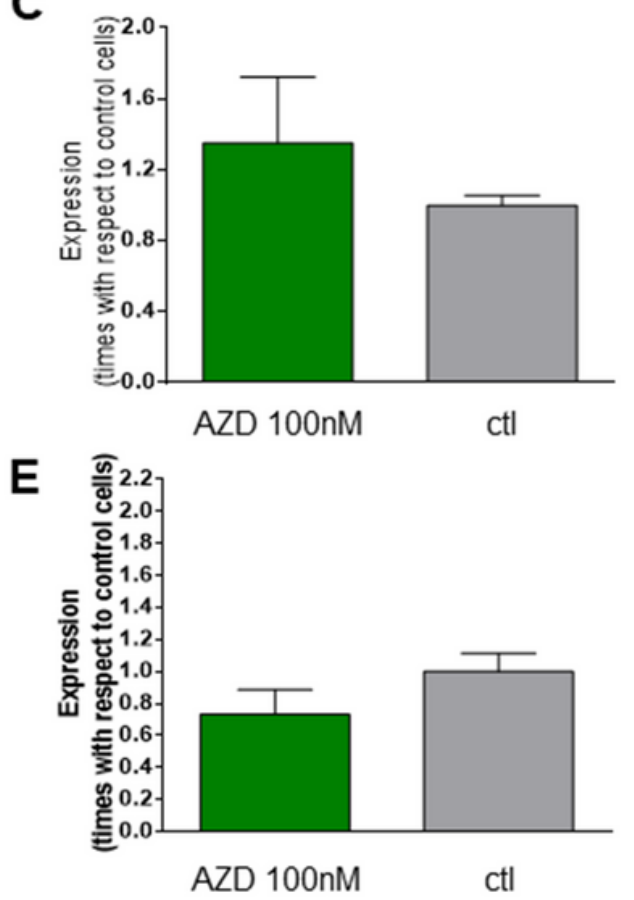

B
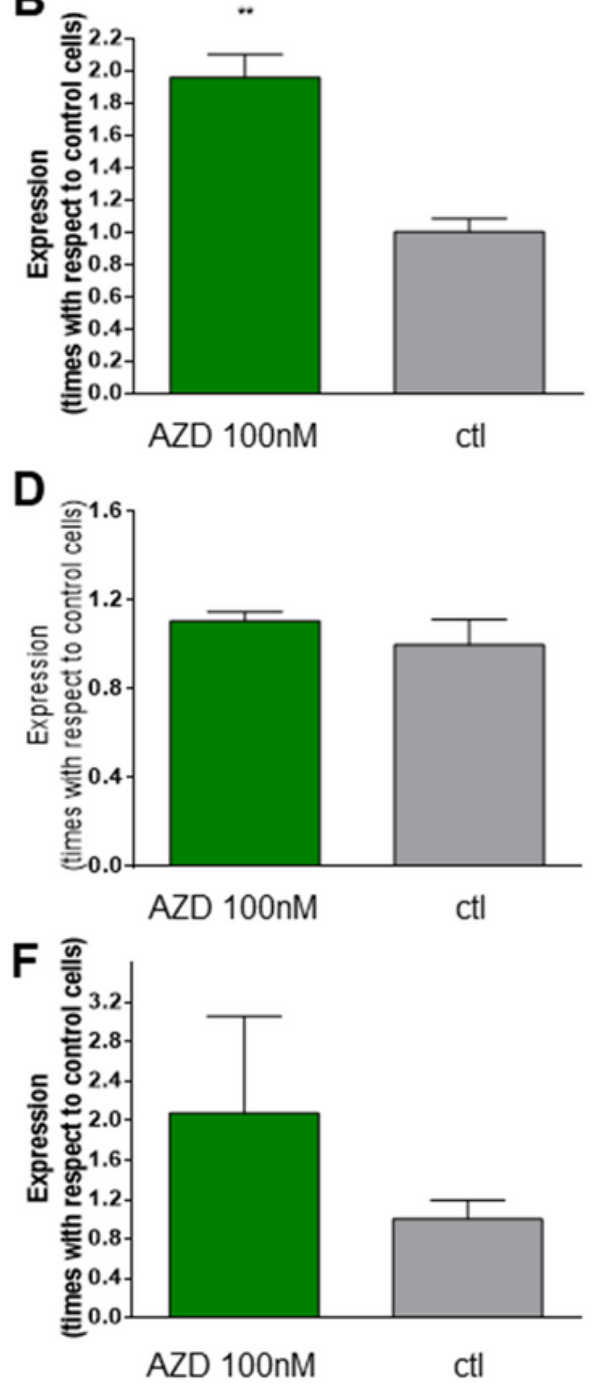

\section{Figure 3}

NHE-1, V-ATPase and CA-IX relative expression in AZD3965-treated cells. NHE-1, V-ATPase and CA-IX relative expression in OE33 ( $A, C$ and $E$ respectively) and OACM5.1C cells ( $B, D$ and $F$ ) was evaluated by RT-qPCR after treatment with AZD3965 (100nM) for 48 hours and the results are expressed as the level of expression of the transporters with respect to cells treated with the vehicle alone. GAPDH and HPRT1 were selected as housekeeping genes. Significant level ${ }^{\star *} p<0.01$. 

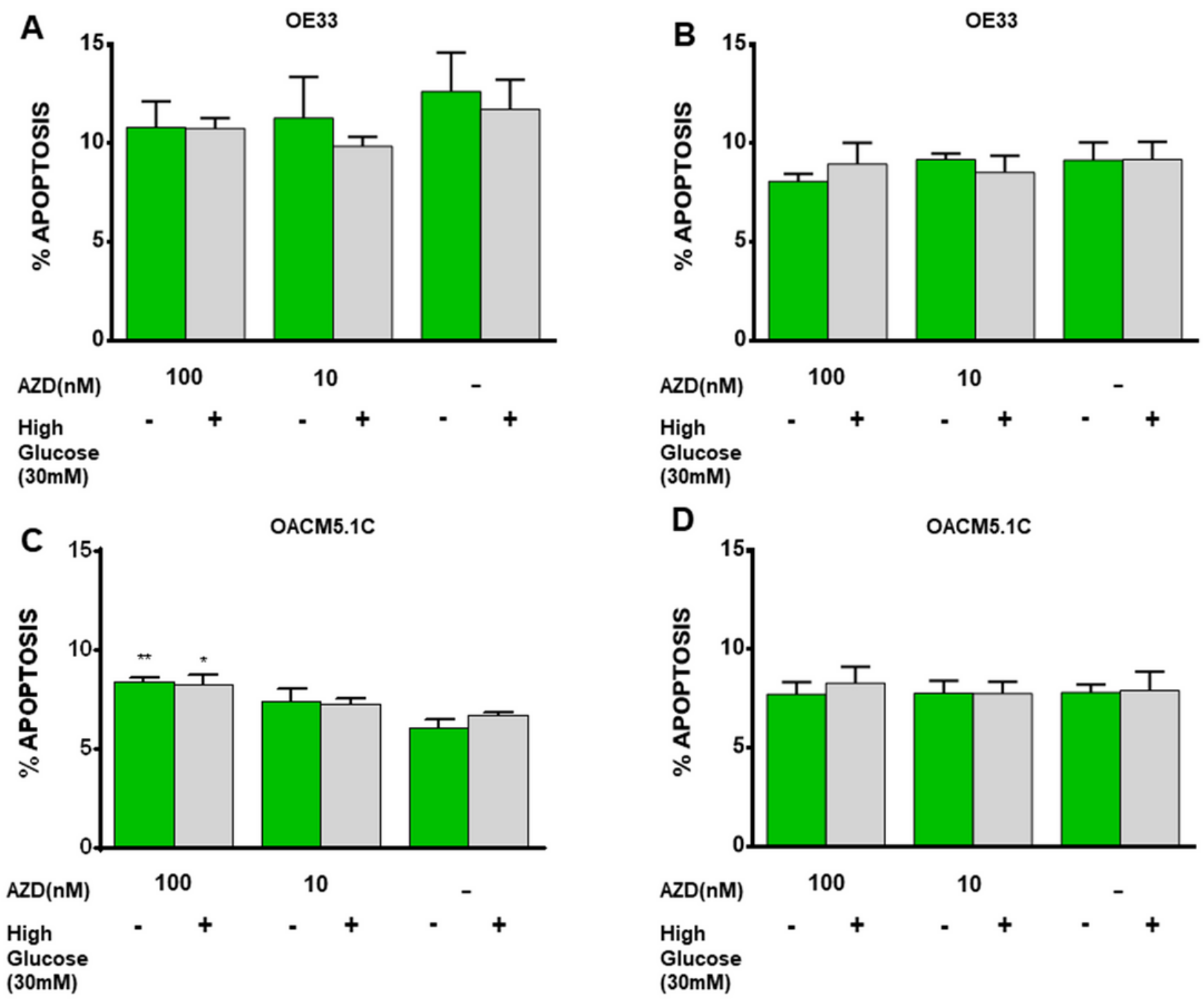

Figure 4

Effects of AZD3965 on apoptosis of EAC cell lines. Apoptosis was evaluated in OE33 (A, B) and OACM5.1C (C, D) cells in normoxia or hypoxia respectively in the presence or absence of a glucose overload (30mM). The bars represent the mean \% of apoptosis in AZD3965-treated cells with respect to control cells (DMSO only). All data are expressed as mean \pm SEM of four independent experiments. Significant level ${ }^{\star} p<0.05 ; * \star p<0.01$. 
A
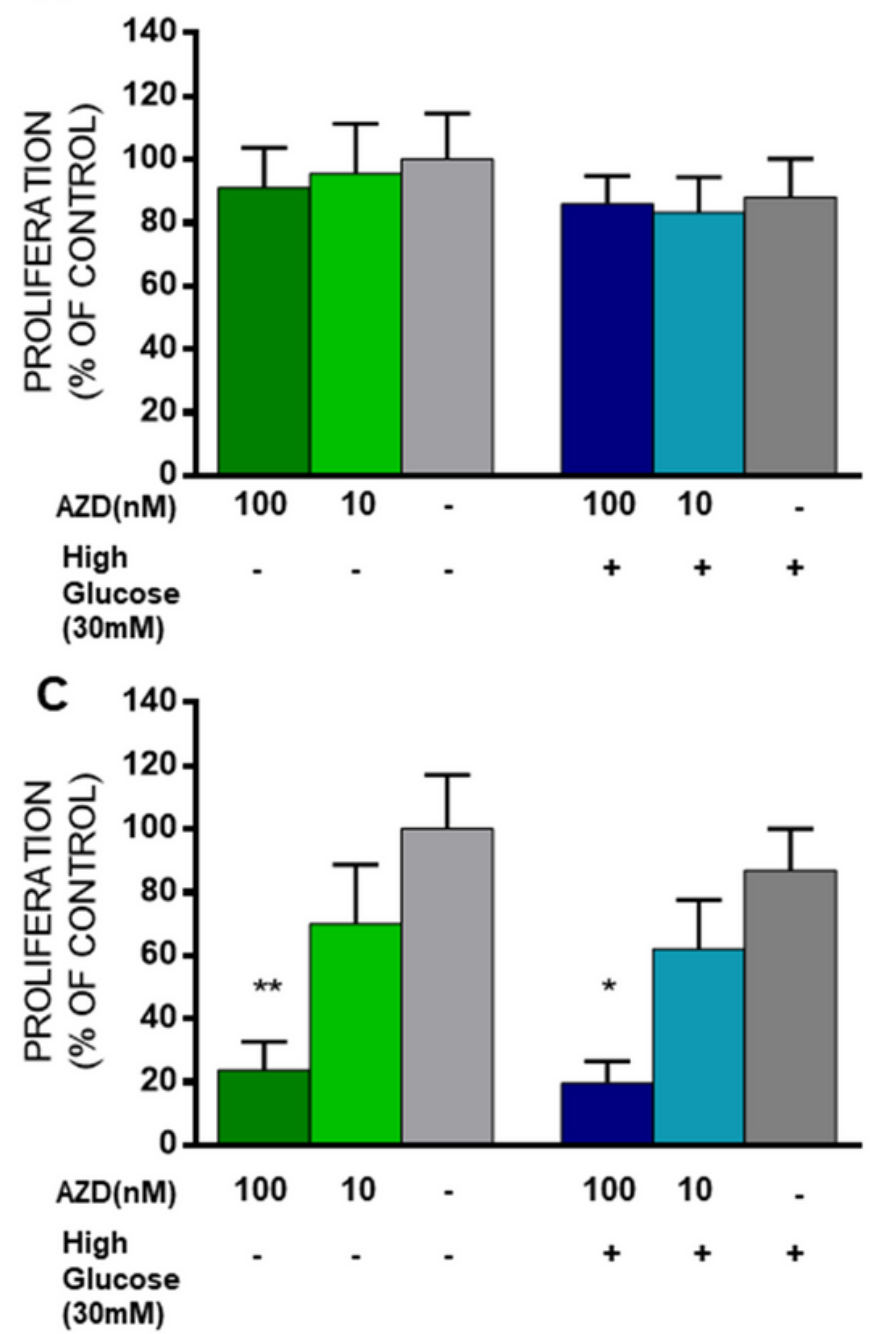

B
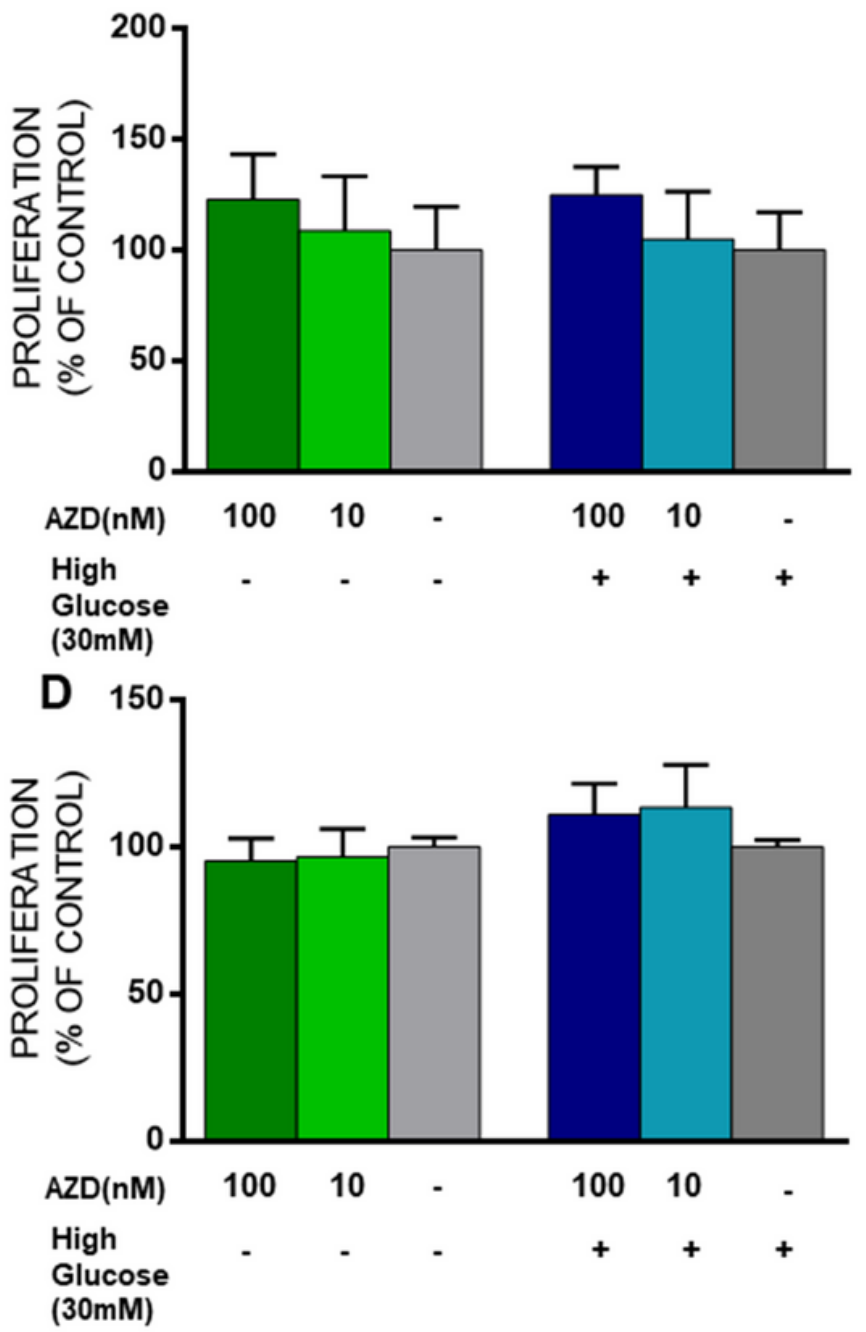

Figure 5

Effects of AZD3965 on cell proliferation. Cell proliferation in OE33 (A, B) and OACM5.1C (C, D) cells in normoxia or hypoxia in the presence or absence of a glucose overload $(30 \mathrm{mM})$. The results are represented as the percentage of BrdU incorporation in AZD3965-treated cells in comparison with untreated controls (DMSO only). All data are expressed as mean \pm SEM of four independent experiments. Significant level * $\mathrm{p}<0.05 ;{ }^{* *} \mathrm{p}<0.01$. 
A

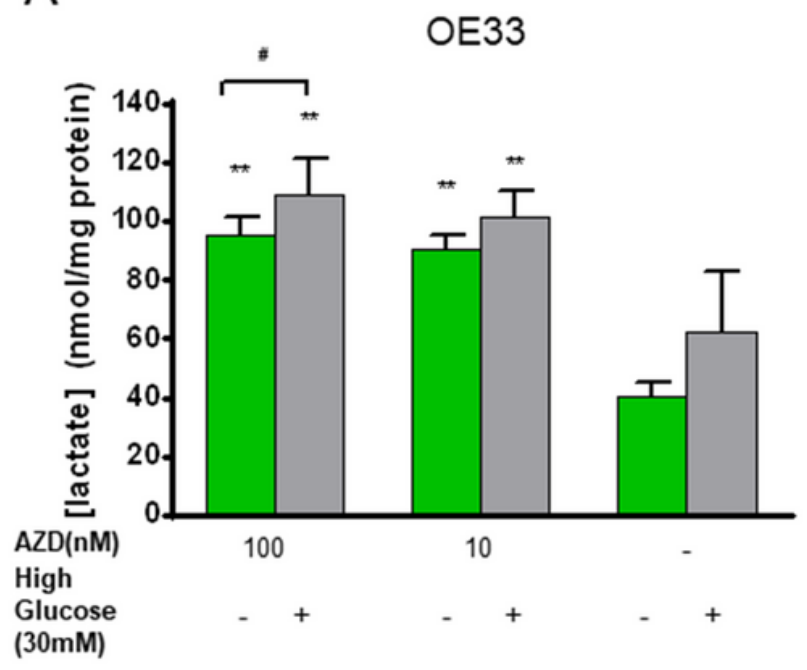

$\mathrm{B}$

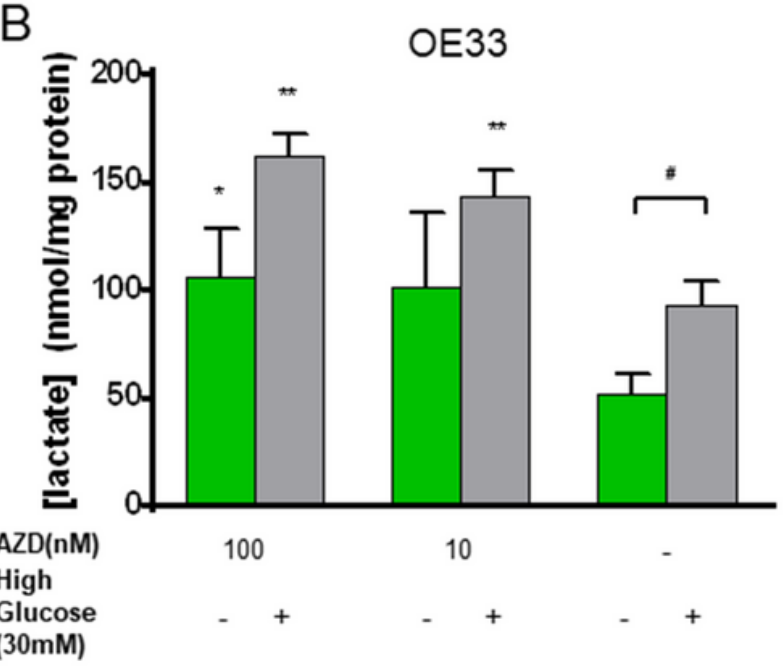

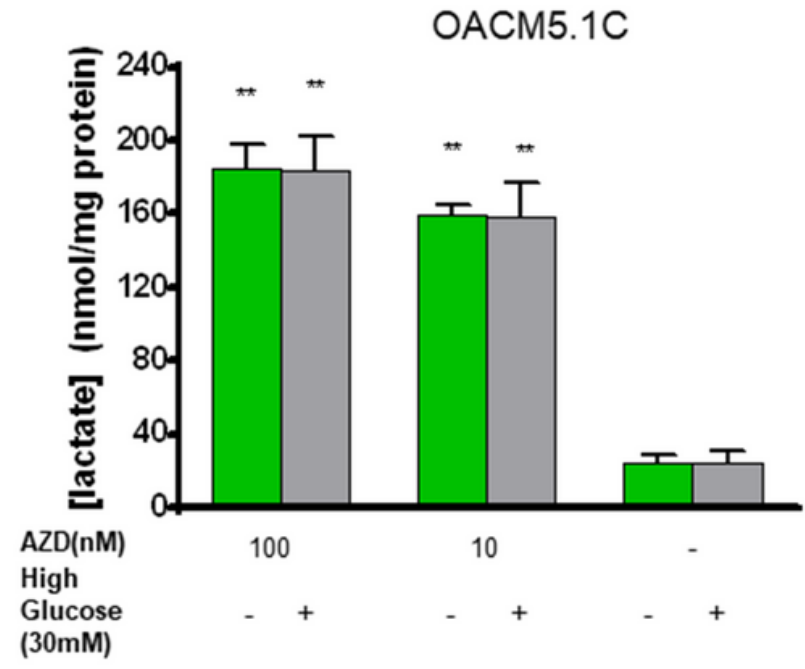

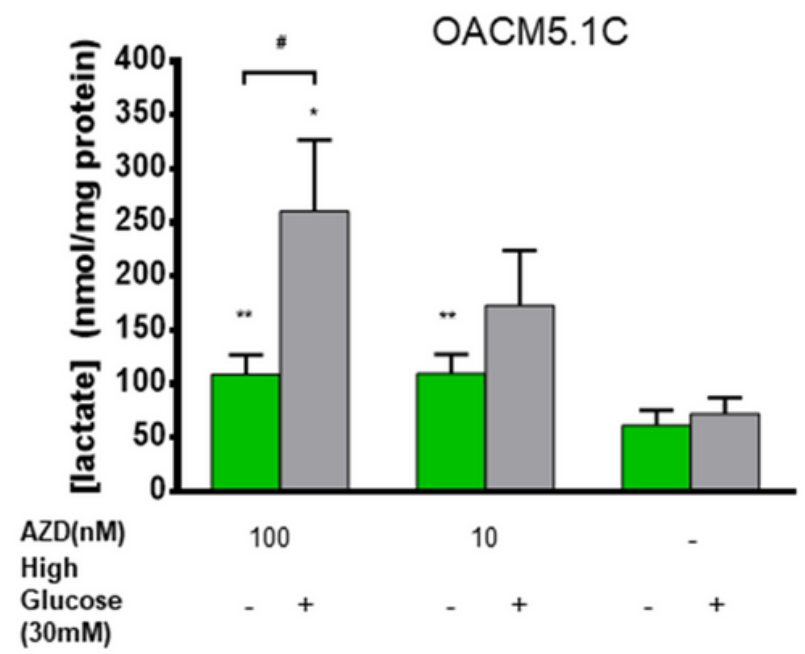

Figure 6

Effects of AZD3965 on intracellular lactate levels. Intracellular lactate levels in normoxia (A) or hypoxia (B) in the presence or absence of a glucose overload (30mM). The results are expressed as nmol lactate/mg protein in AZD3965-treated cells in comparison with untreated controls (DMSO only). All data are expressed as mean $\pm S E M$ of at least three independent experiments. Significant differences from their respective control values: ${ }^{*} p<0.05 ;{ }^{*} p<0.01$. Significant differences from the respective treatment in the presence or absence of a glucose overload: $\# p<0.05$. 
A

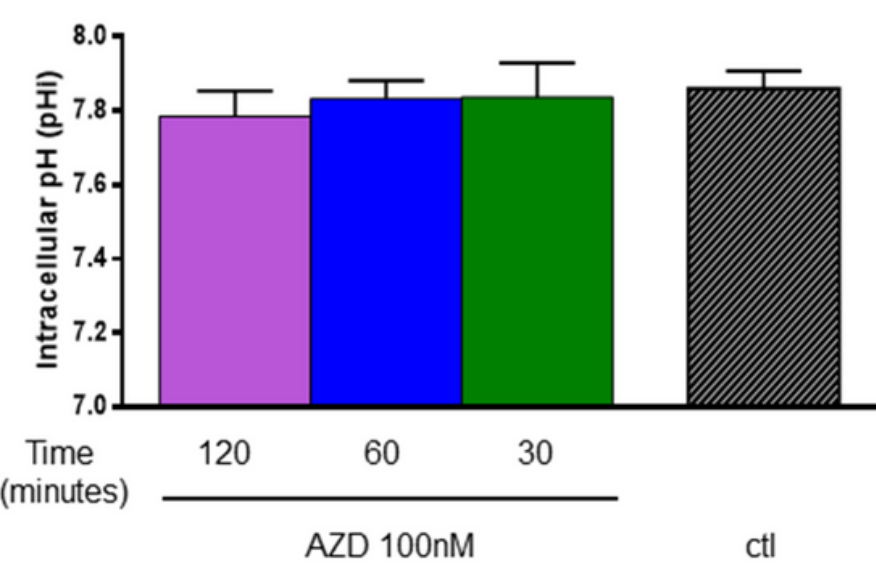

$\mathrm{B}$

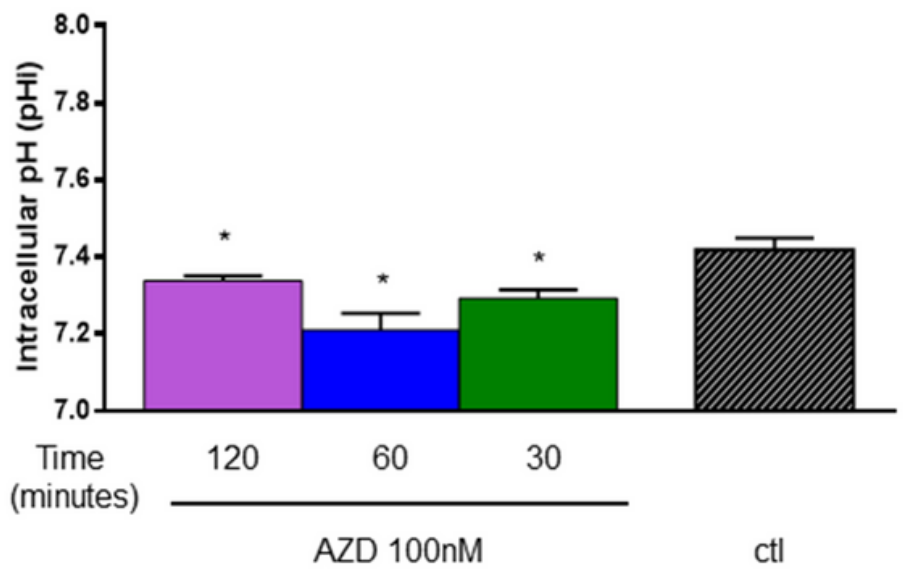

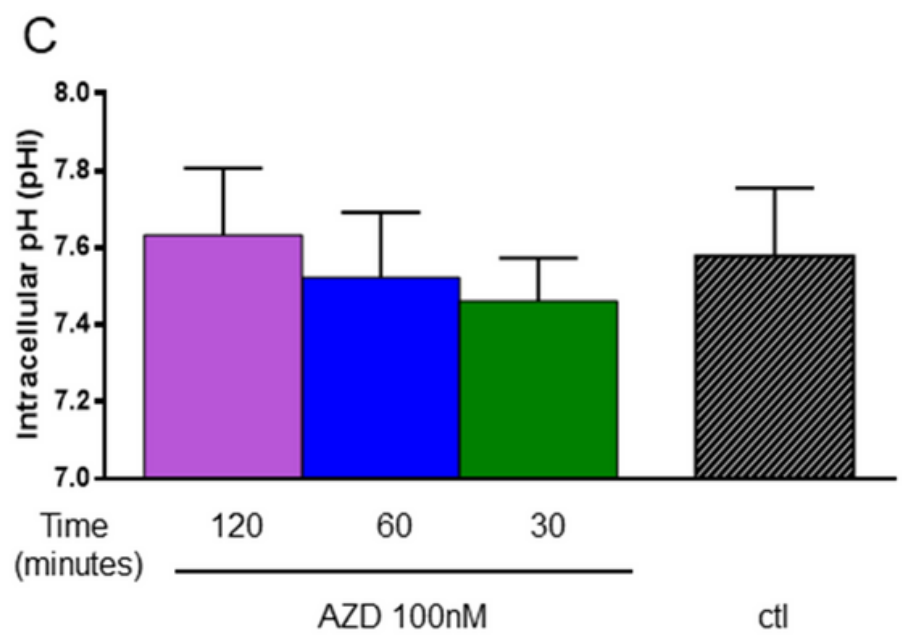

Figure 7

Effects of AZD3965 on intracellular pH. pHi was evaluated at 30,60 and 120 minutes after AZD3965 addition in OE33 cells in normoxia (A) and OACM5.1C cells in normoxia (B) or hypoxia (C). Data are represented as mean $\pm S E M$ of three independent experiments. Significant level ${ }^{*} p<0.05$. 


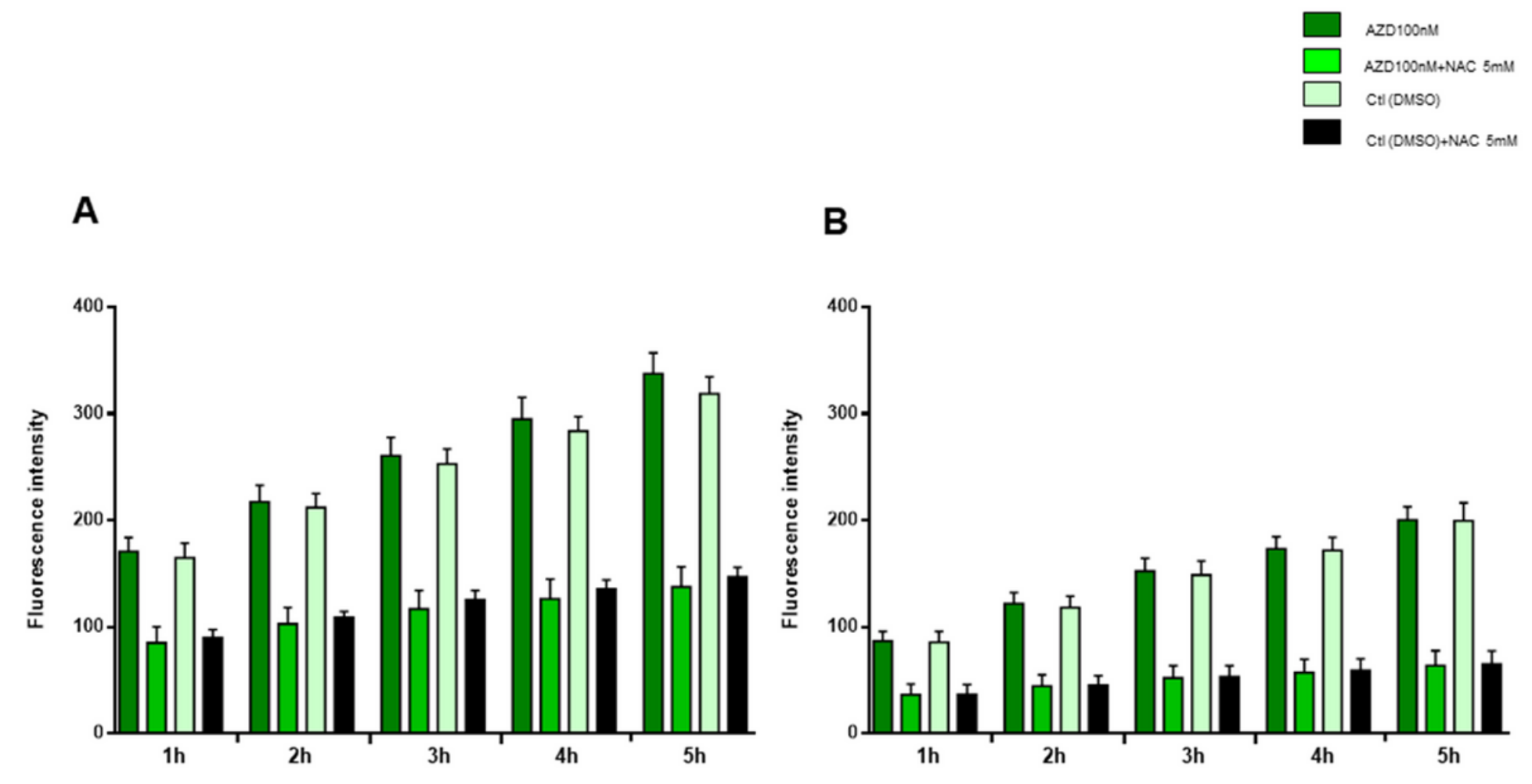

Figure 8

Effects of AZD3965 on ROS production in EAC cells. ROS levels in OE33 (A) and OACM5.1C cells (B) at different time points after the addition of AZD or AZD+the antioxidant NAC. All data are expressed as mean $\pm S E M$ of three independent experiments. Significant differences from the respective treatment in the presence of $N A C * p<0.05$. 